\title{
BMJ Open Long-term musculoskeletal morbidity after adult burn injury: a population-based cohort study
}

\author{
Sean M Randall, ${ }^{1}$ Mark W Fear, ${ }^{2}$ Fiona M Wood, ${ }^{2,3}$ Suzanne Rea, ${ }^{2,3}$ \\ James $\mathrm{H}$ Boyd, ${ }^{1}$ Janine M Duke ${ }^{2}$
}

To cite: Randall SM, Fear MW, Wood FM, et al. Long-term musculoskeletal morbidity after adult burn injury: a population-based cohort study. BMJ Open 2015;5:e009395 doi:10.1136/bmjopen-2015009395

- Prepublication history for this paper is available online To view these files please visit the journal online (http://dx.doi.org/10.1136/ bmjopen-2015-009395)

Received 17 July 2015 Revised 31 July 2015 Accepted 18 August 2015

CrossMark

\begin{abstract}
${ }^{1}$ Centre for Data Linkage, Curtin University, Perth, Western Australia, Australia ${ }^{2}$ Burn Injury Research Unit, School of Surgery, University of Western Australia, Perth, Western Australia, Australia ${ }^{3}$ Burns Service of Western Australia, Royal Perth Hospital and Princess Margaret Hospital, Perth, Western Australia, Australia
\end{abstract}

Correspondence to Professor Janine M Duke; janine.duke@uwa.edu.au

\section{ABSTRACT}

Objective: To investigate if adults who are hospitalised for a burn injury have increased long-term hospital use for musculoskeletal diseases.

Design: A population-based retrospective cohort study using linked administrative health data from the Western Australian Data Linkage System.

Subjects: Records of 17753 persons aged at least 20 years when hospitalised for a first burn injury in Western Australia during the period 1980-2012, and 70758 persons who were age and genderfrequency matched with no injury admissions randomly selected from Western Australia's electoral roll.

Main outcome measures: Admission rates and cumulative length of stay for musculoskeletal diseases. Negative binomial and Cox proportional hazards regression modelling were used to generate incidence rate ratios (IRR) and $\mathrm{HRs}$ with $95 \% \mathrm{Cls}$, respectively.

Results: After adjustment for pre-existing health status and demographic characteristics, the burn cohort had almost twice the hospitalisation rate for a musculoskeletal condition (IRR, $95 \% \mathrm{Cl} 1.98,1.86$ to 2.10), and spent 3.70 times as long in hospital with a musculoskeletal diagnosis ( $95 \% \mathrm{Cl} 3.10$ to 4.42$)$ over the 33-year period, than the uninjured comparison cohort. Adjusted survival analyses of incident postburn musculoskeletal disease admissions found significant increases for the 15-year post burn discharge period (0-6 months: $\mathrm{HR}, 95 \% \mathrm{Cl} 2.51,2.04$ to $3.11 ; 6$ months-2 years: HR, $95 \% \mathrm{Cl} 1.77,1.53$ to 2.05; 2-15 years: HR, $95 \% \mathrm{Cl} 1.32,1.23$ to 1.42 ). Incident admission rates were significantly elevated for 20 years post-burn for minor and severe burn injury for a range of musculoskeletal diseases that included arthropathies, dorsopathies, osteopathies and soft tissue disorders.

Conclusions: Minor and severe burn injuries were associated with significantly increased post-burn incident admission rates, long-term hospital use and prolonged length of stay for a range of musculoskeletal diseases. Further research is required that facilitates identification of at-risk patients and appropriate treatment pathways, to reduce the long-term morbidity associated with burns.

\section{Strengths and limitations of this study}

- Population-based linked administrative health data provide a cost-effective means to examine long-term health impacts of burn injury.

- Population-based linked administrative health data minimise issues of selection and reporting bias, and loss to follow-up.

- The retrospective longitudinal study design included a comparison group.

- Lack of individual-based risk factor data.

- Small proportion of patient population with severe burns limited examination of long-term effects.

\section{INTRODUCTION}

Despite advances in surgical and medical treatment, burn injuries continue to present significant challenges to clinicians, and to burn survivors, often leading to long-term psychological and physical impairments. ${ }^{1}$ It is well documented that severe burn injury induces acute inflammatory and hypermetabolic responses that persist for at least 2 years after the initial injury. ${ }^{2} 3$ The subsequent metabolic demands and energy requirements are profound and induce mobilisation of proteins and amino acids, resulting in an associated increase in protein turnover, degradation and negative nitrogen balance, characteristics of serious illness. ${ }^{4}$ The physiological impacts of hypermetabolism include protein catabolism, losses of body weight, lean body mass and bone mineral density. ${ }^{5} 6$

In addition to the hypermetabolic response and muscle wasting there is extensive and sustained suppression of bone formation as a result of the systemic inflammatory and endocrine responses to severe burn injury. ${ }^{7-9}$ Muscle wasting and immobility after burn injury can also directly alter the balance of bone synthesis and degradation, leading to bone loss. ${ }^{7-11}$ Burn 
patients are also at risk of vitamin D deficiency, contributing to bone loss. ${ }^{12-15}$ Vitamin D deficiency may develop progressively as a result of a number of factors including prolonged sun avoidance during treatments, ${ }^{16}$ hypoparathyroidism ${ }^{17} 18$ and low serum levels of cholesterol evident after burn injury, ${ }^{19}{ }^{20}$ preventing the synthesis and activation of vitamin D. In adults and children, loss of bone mass and changes in bone density predispose burn patients to an increased incidence of fractures and potentially to lifelong issues associated with osteoporosis. $^{71114152122}$

Minor burn injuries represent the majority of burn related hospital admissions in developed countries, ${ }^{23} 24$ and there is a growing interest in understanding the potential for systemic responses after non-severe burns. Recent research has demonstrated long-term impacts after minor burn injury on bone marrow, ${ }^{25}$ muscle, innervation and bone, ${ }^{26-28}$ with population-based findings of increased cancer incidence ${ }^{29} 30$ and long-term mortality. ${ }^{31}{ }^{32}$ Non-severe burn injury has also been found to have a sustained impact on reducing trabecular bone density long after resolution of inflammation. ${ }^{27}$ However, the clinical relevance of these bone alterations is not yet clear. Investigation of the long-term effects of severe and minor burn injury is important to provide evidence for improvements in acute burn care.

To date, limited data have been available to examine the long-term health impacts of burns. Population-based linked health administrative data provide a cost-effective means to examine long-term morbidity trends expressed in the number of hospital admissions and length of stay for specific disease classifications. ${ }^{33}$ Given the profound growth and musculoskeletal changes experienced during childhood and adolescence with the potential for different post-burn impacts, this study was limited to data of adult burn survivors 20 years and above. The aim of this study was to use population-based linked health administrative data to determine if adults hospitalised for a burn injury have increased long-term hospital use for musculoskeletal diseases, after adjustment for sociodemographic factors and pre-existing comorbidities.

\section{METHODS}

Our study formed part of the Western Australian Population-based Burn Injury Project-a retrospective cohort investigation-that uses administrative health data from the Western Australian Data Linkage System (WADLS), a validated linkage system that links several core datasets for the entire population of Western Australia. ${ }^{34}$ The project was approved by the human research ethics committees of the University of Western Australia and the Western Australian Department of Health.

Analyses were performed on a de-identified extraction of hospital morbidity records for all individuals who were aged at least 20 years when admitted to a hospital in Western Australia with a first burn injury between
1 January 1980 and 30 June 2012, undertaken by the WADLS. A first (index) burn injury was defined as the first hospital admission in a patient's medical record in which a burn injury was given as the principal diagnosis or an additional diagnosis, defined by International Classification of Diseases and Related Health (ICD) 9 CM 940-949 or ICD10 AM T20-T31. A population-based comparison cohort was randomly selected from Western Australia's electoral roll. Any person with an injury hospitalisation during the study period was excluded from this cohort by WADLS staff. The resultant comparison cohort was frequency matched (4:1) on birth year and sex of each burn injury case for each year from 1980 to 2012. Cohort selection and analytical methods have been reported previously. ${ }^{31}$

Data from Western Australia's Hospital Morbidity Data System and Death Register were linked to the burn and non-injured cohorts for the period 1980-2012. Hospital admissions data included principal and additional diagnoses, age at admission, sex, and Aboriginal status, date of admission, date of discharge or other separation and mode of separation. Data supplied for the burn and non-injured cohorts also included geocoded place of residence and geocoded indices of geographical remoteness ${ }^{35}$ and social disadvantage. ${ }^{36}$ Geographical remoteness was classified into five categories: major cities, inner regional, outer regional, remote and very remote. The social disadvantage index was reclassified into quintiles (most to least disadvantaged). The mortality data included date of death and cause of death.

An individual listed as Aboriginal or Torres Strait Islander on any admission record was categorised as Aboriginal. Supplementary codes ICD9-CM 948 or ICD10-AM T31 were used to classify the patients into those with minor burns $(<20 \%$ of total body surface area (TBSA)), severe burns ( $\geq 20 \%$ TBSA) and burns of unspecified TBSA. Comorbidity (baseline) was assessed, with a 5-year look-back period, using the Charlson Comorbidity Index (CCI) and the principal and additional diagnoses included in the hospital morbidity records $(0 \mathrm{CCI}=0 ; 1 \mathrm{CCI} \geq 1) .{ }^{37}{ }^{38} \mathrm{~A}$ record of an existing congenital anomaly was identified using principal and additional diagnosis data (ICD9 740-759; ICD10 Q00-G99). The final discharge date for the index burn admission was used as the study start for follow-up for the burn cases and the respective frequency matched non-injury controls.

Categorical and non-parametric continuous variables were compared using $\chi^{2}$ and Kruskal Wallis tests, respectively. A p value of 0.05 or lower was considered statistically significant. The total number of admissions for musculoskeletal disorders after burn injury discharge and the cumulative length of stay for principal diagnosis musculoskeletal disorders classified by subchapter headings were used as outcome measures (ICD10 AM: M00-M25-arthropathies (including infectious and inflammatory arthropathies, arthrosis and other joint disorders); M30-M36-systemic connective tissue 
disorders; M40-M54-dorsopathies (including deforming spinal conditions, spondylopathies and other disorders of the spine); M60-M79—soft tissue disorders (including disorders of muscles, synovium and tendons, other soft tissue disorders); M80-M94-osteopathies and chrondropathies (including disorders of bone density, osteopathies and chrondropathies). ICD-10 codes were mapped to ICD-9 codes. ${ }^{39}$ The hospitalisation of the first burn injury was not included in these outcomes. Crude yearly admission rates were calculated for these variables. Adjusted rate ratios (incidence rate ratio (IRR) and $95 \% \mathrm{CI}$ ) between the burn injury and no injury cohorts and the outcome measures were generated using negative binomial regression. Sociodemographic (gender, Aboriginality, 5-year age group, social disadvantage, remoteness of residence and year of admission) and health status information (comorbidity at baseline, history of musculoskeletal disease, congenital anomaly) were included as covariates in the models to adjust for potential confounding.

Survival analyses of incident hospital use for arthropathies, systemic connective tissue disorders, dorsopathies, soft tissue disorders, osteopathies and chrondropathies (ie, ICD subchapter headings) as well as specific subsets of musculoskeletal diseases, infectious arthropathy, inflammatory polyarthropathy and disorders of bone density and structure, were conducted using multivariate Cox proportional hazards models. Analyses were conducted on the burn and uninjured cohorts excluding those with prior admission for musculoskeletal disease, and additionally, excluding those with a record of an injury admission in the burn cohort. Cox models were adjusted for sociodemographic and health status variables (as above). Analyses were undertaken of subgroups by burn TBSA severity and gender-specific analyses were undertaken to explore potential gender dimorphic differences in disease incidence. The proportional hazard assumption for the burn injured versus noninjured was tested using scaled and unscaled Schoenfeld residuals and by adding a group-by-time interaction term. ${ }^{40}$ Where preliminary analyses showed nonproportionality, adjusted HR and 95\% CI for first record of musculoskeletal admission for burn versus non-injury cohorts were modelled for time periods guided by Aalen's linear hazard models and plots. ${ }^{41}$

Attributable risk percentages (AR\%) were calculated as the adjusted rate ratio (IRR, HR) minus one, divided by the adjusted rate (IRR, HR) ratio, multiplied by $100 .{ }^{42} \mathrm{AR} \%$ was used to estimate the proportion of longterm and incident hospital use for musculoskeletal diseases, where burn injury was a component cause. ${ }^{43}$ Statistical analyses were performed using Stata V.12 (StataCorp. LP, College Station, Texas, USA).

\section{RESULTS}

The burn injury cohort included 17753 persons aged at least 20 years when hospitalised for a first burn injury during the period January 1980-June 2012. The median age was 36 (IQR: 26-51) and $71.1 \%$ were male. Four per cent had severe burns of 20\% TBSA or greater, $49 \%$ had burns of less than 20\% TBSA and for $47 \%$, the TBSA was unspecified. Eighteen per cent of the burn cohort had sustained full thickness burns, 37\% partial thickness, $19 \%$ erythema and 29\% had experienced burns for which the burn depth was unspecified; an individual may have had multiple burns sites and depths recorded. Among the burn cohort, 34\% had a record of a non-burn injury admission (before or after index burn), and $13.8 \%$ had a previous musculoskeletal hospital admission. The burn injury cohort had a median follow-up time of 13.6 years (IQR; minimum (min)maximum $(\max )$ : 5.5-22.7; >0-32.5) for a total of 250670 person years.

The comparison non-injury cohort comprised 70758 persons with median age 41 (IQR: 27-51) and males accounting for $71.0 \%$. The uninjured cohort had a median follow-up time of 14.5 years (IQR; min-max: 6.9-23.1; 0.01 to 32.5) for a total of 1067568 person years. Refer to table 1 for other baseline sociodemographic and health status variables for the burn and non-injury cohorts. The burn injury cohort comprised significantly higher proportions of Aboriginal people, people who were socially disadvantaged, people living in regions outside of major cities and people who had preexisting comorbidity when compared with the noninjured comparison cohort.

\section{Admissions for diseases of musculoskeletal system—rates and cumulative length of stay}

There were 10761 hospital admissions occurring after burn hospitalisation discharge with a primary diagnosis of a musculoskeletal disease. Arthropathies were the most common cause of musculoskeletal admission, followed by dorsopathies (see table 2). A total of 55810 days were spent in hospital for musculoskeletal diagnosis after a burn hospitalisation. The median length of hospital stay was 1 day (IQR: $0-5$ days). The total number of days spent in hospital with a musculoskeletal primary diagnosis by the uninjured cohort was 68946 , where the median length of stay of musculoskeletal admissions was 1 day (IQR: 0-3 days). The length of stay of 0 days represents admission and discharge occurring on the same day.

Unadjusted incidence rates for musculoskeletal admissions and lengths of stay are shown in figure 1 . These graphs show a higher rate of admissions for musculoskeletal diseases, and more time spent in hospital with musculoskeletal diseases for burn patients compared with uninjured patients over the entire 33-year period.

After adjustment for pre-existing health and sociodemographic characteristics, the burn cohort had almost twice as many hospitalisations for a musculoskeletal condition (IRR, 95\% CI 1.98, 1.86 to 2.10 ), and spent 3.70 times as long in hospital with a musculoskeletal diagnosis $(95 \%$ CI 3.10 to 4.42$)$ over the 33-year period, than 
Table 1 Baseline demographic and pre-existing health status factors for the burn injury (total) and the frequency matched non-injury (total) cohorts

\begin{tabular}{|c|c|c|c|}
\hline Characteristics & $\begin{array}{l}\text { No injury } \\
\mathrm{N}(\%)\end{array}$ & $\begin{array}{l}\text { Burn injury } \\
N(\%)\end{array}$ & p Value \\
\hline Total & 70758 & 17753 & \\
\hline \multicolumn{4}{|l|}{ Demographic } \\
\hline \multicolumn{4}{|l|}{ Aboriginality } \\
\hline Yes & $809(1.1)$ & $2139(12.0)$ & $<0.001$ \\
\hline \multicolumn{4}{|l|}{ Social disadvantage quintiles* } \\
\hline Quintile 1 (most disadvantaged) & $8307(11.8)$ & $3716(21.4)$ & $<0.001$ \\
\hline Quintile 2 & $15623(22.1)$ & $5536(31.8)$ & \\
\hline Quintile 3 & $12930(18.3)$ & $3681(21.2)$ & \\
\hline Quintile 4 & $12988(18.4)$ & 2207 (12.7) & \\
\hline Quintile 5 (least disadvantaged) & $20738(29.4)$ & 2255 (13.0) & \\
\hline \multicolumn{4}{|l|}{ Remotenesst } \\
\hline Major city & $53358(75.6)$ & 8965 (51.5) & $<0.001$ \\
\hline Inner regional & $6564(9.3)$ & 1954 (11.2) & \\
\hline Outer regional & $6036(8.6)$ & $2783(16.0)$ & \\
\hline Remote & $2789(4.0)$ & $1913(11.0)$ & \\
\hline Very remote & $1839(2.6)$ & $1803(10.4)$ & \\
\hline \multicolumn{4}{|l|}{ Health status } \\
\hline \multicolumn{4}{|l|}{ Comorbidity $\dagger$} \\
\hline Any (Charlson Comorbidity Index, $\mathrm{CCl} \geq 1$ ) & $4,132(5.8)$ & $2833(16.0)$ & $<0.001$ \\
\hline Prior admission for disease of musculoskeletal system§ & $3889(5.5)$ & 2455 (13.8) & $<0.001$ \\
\hline
\end{tabular}

Table 2 Number of admissions (\%) for musculoskeletal diseases classified by ICD subchapter codes in the non-injury and burn injury cohorts

\begin{tabular}{|c|c|c|}
\hline \multirow{2}{*}{$\begin{array}{l}\text { Musculoskeletal } \\
\text { subconditions }\end{array}$} & \multicolumn{2}{|c|}{$\begin{array}{l}\text { Number of admissions } \\
(\%)\end{array}$} \\
\hline & No injury & Burn injury \\
\hline Total & 20223 & 10761 \\
\hline Arthropathies & $9513(47.0)$ & $4362(40.5)$ \\
\hline Infectious arthropathy & $82(0.4)$ & $153(1.4)$ \\
\hline $\begin{array}{l}\text { Inflammatory } \\
\text { polyarthropathy }\end{array}$ & $620(3.1)$ & $795(7.4)$ \\
\hline Osteoarthritis & 3706 (18.3) & $1346(12.5)$ \\
\hline Other joint disorders & 5105 (25.2) & $2068(19.2)$ \\
\hline Dorsopathies & 5620 (27.8) & 3584 (33.3) \\
\hline Spondylopathies & $1571(7.8)$ & $747(6.9)$ \\
\hline Other dorsopathies & 3918 (19.4) & $2747(25.5)$ \\
\hline $\begin{array}{l}\text { Osteopathies and } \\
\text { chrondropathies }\end{array}$ & $772(3.8)$ & $764(7.1)$ \\
\hline $\begin{array}{l}\text { Disorders of bone density } \\
\text { and structure }\end{array}$ & $366(1.8)$ & 355 (3.3) \\
\hline Soft tissue disorders & 3809 (18.8) & $1747(16.2)$ \\
\hline Disorder of muscles & $95(0.5)$ & $79(0.7)$ \\
\hline $\begin{array}{l}\text { Disorders of synovium/ } \\
\text { tendons }\end{array}$ & $833(4.1)$ & $324(3.0)$ \\
\hline Other soft tissue disorders & $2881(14.2)$ & $1344(12.5)$ \\
\hline Connective tissue disorders & $143(0.7)$ & $64(0.6)$ \\
\hline Other & $366(1.8)$ & $243(2.3)$ \\
\hline
\end{tabular}

the uninjured comparison cohort. The adjusted AR\% suggested that the burn cohort experienced an excess of $49.5 \%$ of admissions for musculoskeletal conditions $(\mathrm{n}=5329)$ and $73.0 \%$ of all days spent in hospital for musculoskeletal conditions ( $\mathrm{n}=40727$ days), when compared to the uninjured cohort.

Unadjusted admission rates for the musculoskeletal system sub-categories are shown in figure 2. After controlling for demographic factors and previous health status, those who had a burn had higher rates of admissions for arthropathies (IRR, 95\% CI 1.64, 1.54 to 1.75), dorsopathies (IRR, 95\% CI 2.16, 1.93 to 2.41), osteopathies and chondropathies (IRR, 95\% CI 5.64, 4.56 to 6.97 ) and soft tissue disorders (IRR, 95\% CI 1.91, 1.76 to 2.06). There was no difference in the rate of admissions for connective tissue disorders between the burn and the non-injured cohorts (IRR, 95\% CI $0.88,0.48$ to 1.62). The adjusted AR\% suggested that the burn cohort experienced excess post-burn admissions of $39.0 \%$ for arthropathies $(\mathrm{n}=1702), 53.7 \%$ for dorsopathies $(n=1925), 82.3 \%$ for osteopathies and chrondropathies $(n=629)$, and $47.6 \%$ for soft tissue disorders $(\mathrm{n}=832)$, when compared with the uninjured cohort.

Examination of more specific subconditions showed a large and significant increase in the rate of admissions for disorders of bone density (IRR, 95\% CI 13.87, 9.89 to 19.44), along with increases in infectious arthropathies (IRR, 95\% CI 1.98, 1.46 to 2.69 ) and inflammatory 
Figure 1 Unadjusted rates of hospital admissions and cumulative length of stay (per 100 person-years (PYs)) for musculoskeletal diseases (total) among adults with burn injury versus no injury.
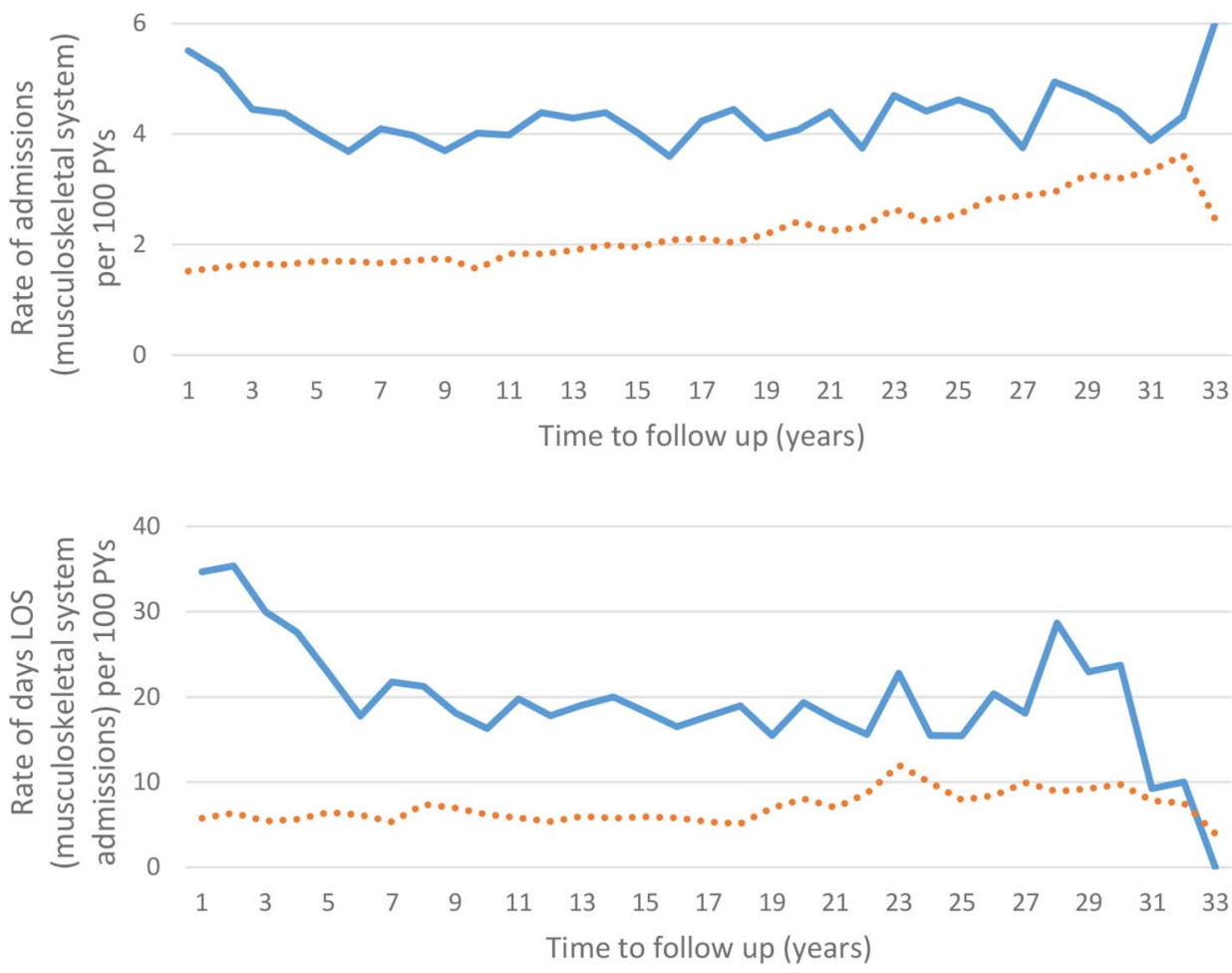

— Burn Injury $\ldots$... No Injury

Arthropathies

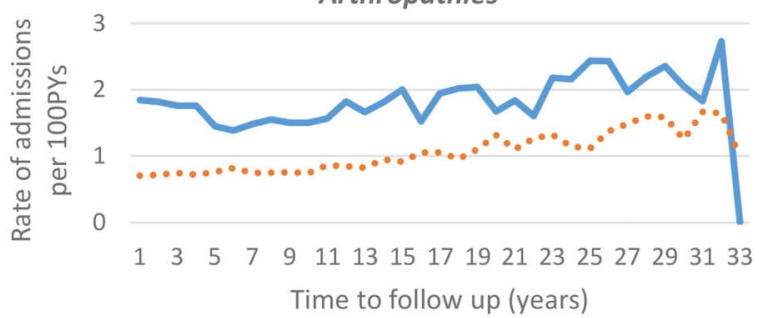

Dorsopathies

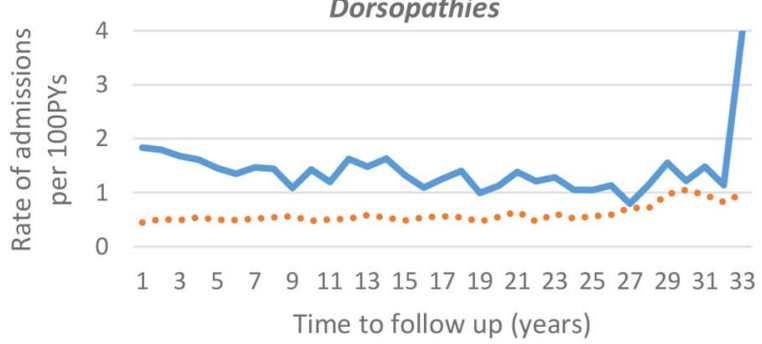

Soft Tissue Disorders

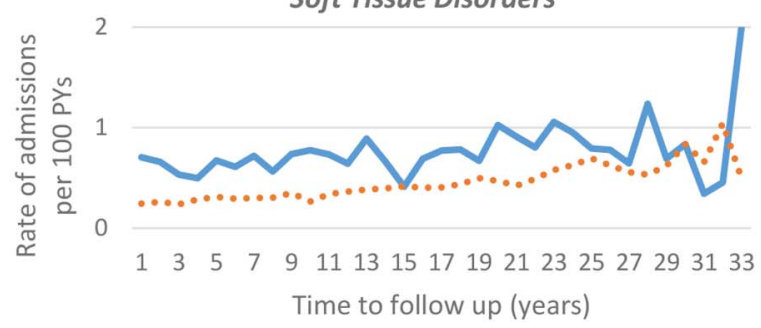

Connective Tissue Disorders

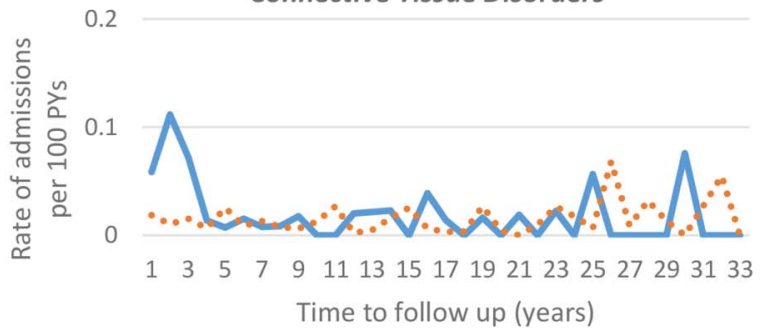


polyarthropathies (IRR, 95\% CI 3.82, 2.61 to 5.59 ) for those hospitalised with a burn injury.

A similar picture was shown for the length of time spent in hospital, with longer cumulative length of stay after a burn hospitalisation with arthropathies (IRR, $95 \%$ CI $1.64,1.54$ to 1.75 ), dorsopathies (IRR, 95\% CI $2.16,1.93$ to 2.41), osteopathies and chondropathies (IRR, 95\% CI: 5.64, 4.56 to 6.97 ), and soft tissue disorders (IRR, 95\% CI 1.91, 1.76 to 2.06). Those with a burn injury spent almost 50 times longer in hospital with disorders of bone density compared to the uninjured cohort (IRR, 95\% CI 49.24, 28.72 to 84.42), with increases in cumulative time spent in hospital also found for infectious arthropathies (IRR, 95\% CI 13.1, 5.62 to 30.56 ) and inflammatory polyarthropathies (IRR, 95\% CI $1.98,1.46$ to 2.69 ). No significant difference was found between the burn and uninjured cohorts for length of time in hospital with connective tissue disorders (IRR, 95\% CI 0.65, 0.23 to 1.85 ).

Analysis by TBSA severity (see table 3) showed that increased hospitalisation rates were associated with severe and minor burns, with those with minor burns having higher admission rates for arthropathies, dorsopathies, osteopathies and chondropathies, and soft tissue disorders when compared with the uninjured cohort.

\section{Incidence-survival analysis}

Analysis of time until first musculoskeletal admission (post-burn) was performed on the burn and uninjured cohorts who did not have a prior record of musculoskeletal hospitalisation, with the additional exclusion from the burn cohort of those with a record of a principal diagnosis injury admission. There were 10440 individuals in this reduced burn cohort, of which 1779 had a first time (incident) musculoskeletal admission within the study period. The uninjured comparison cohort comprised of 66869 controls, of which 9689 had an incident musculoskeletal admission in this study period.

Results of multivariate Cox regression modelling for an incident musculoskeletal (combined diseases) admission revealed evidence of non-proportionality. First time musculoskeletal (combined diseases) admissions were most frequent immediately after burn and while remaining significantly elevated, decreased over the study period. Adjusted analyses conducted on partitioned time windows found significant HRs for the first 6 months after burn (HR, 95\% CI 2.51, 2.04 to 3.11), from 6 months to 2 years after burn (HR, 95\% CI 1.77 , 1.53 to 2.05), and from 2 to 15 years after burn (HR, $95 \%$ CI $1.32,1.23$ to 1.42). Differences were found for severe (HR, 95\% CI 4.37, 2.32 to 8.25), minor (HR, 95\% CI 2.25, 1.68 to 3.01) and unknown TBSA (HR, 95\% CI 2.42, 1.74 to 3.37 ) for the first 6 months; only minor burns (HR, 95\% CI 6 months-2 years; 1.68, 1.39 to 2.04, 2-15 years; $1.44,1.30$ to 1.59 ) and unknown TBSA burns (HR, 95\% CI 6 months-2 years; $1.83,1.54$ to 2.17 , 2 15 years; $1.28,1.17$ to 1.41 ) showed increased admissions over the first 15 years.

After adjustment for confounders, both males (HR, 95\% CI 0-6 months; 2.62, 2.03 to 3.39, 6 months2 years; $1.83,1.54$ to $2.17,2-15$ years; $1.31,1.21$ to 1.42 ) and females (HR, 95\% CI 0-6 months; 2.09, 1.35 to 3.23 , 6 months-2 years; $1.68,1.27$ to $2.23,2-15$ years; $1.34,1.17$ to 1.53 ) with burns showed significant increases over the first 15 years post-burn, compared with uninjured males and females, respectively.

In the burn cohort, there were 968 first time admissions for arthropathies, 468 for dorsopathies, 155 for osteopathies and chrondropathies $(\mathrm{n}=70$ bone density disorders), 541 for soft tissue disorders and 8 first time admissions for connective tissue disorders. First time admissions for infectious arthropathy and inflammatory polyarthropathy accounted for 24 and 67 of the total incident arthrropathy admissions, with median (IQR) times to incident admission of 8.4 years $(3.4-16.3)$ and 9.4 years (3.8-16.9), respectively. Results for adjusted Cox regression models for incident musculoskeletal subconditions are shown in table 4. Evidence of nonproportionality was common for numerous subconditions, with higher rates of admissions in the burn cohort

Table 3 Adjusted IRR and 95\% Cls for recurrent admissions musculoskeletal subconditions, by burn severity compared with the uninjured cohort

\begin{tabular}{|c|c|c|c|}
\hline Musculoskeletal subconditions & $\begin{array}{l}\text { Severe burns* } \\
\text { IRR }(95 \% \mathrm{Cl}) \dagger\end{array}$ & $\begin{array}{l}\text { Minor burns* } \\
\text { IRR ( } 95 \% \mathrm{CI})\end{array}$ & $\begin{array}{l}\text { Unspecified severity* } \\
\text { IRR }(95 \% \mathrm{CI})\end{array}$ \\
\hline Arthropathies & $1.54(1.20$ to 1.99$)$ & $1.56(1.41$ to 1.73$)$ & $1.71(1.58$ to 1.85$)$ \\
\hline Infectious arthropathy & 6.20 (1.54 to 24.87$)$ & 8.05 (4.37 to 14.82$)$ & $2.23(1.49$ to 3.35$)$ \\
\hline Inflammatory polyarthropathy & 2.91 (1.22 to 6.91$)$ & 1.99 (1.21 to 3.28$)$ & 2.06 (1.48 to 2.86$)$ \\
\hline Dorsopathies & 1.69 (1.06 to 2.68$)$ & 1.98 (1.68 to 2.33$)$ & 2.38 (2.07 to 2.73$)$ \\
\hline Osteopathies and chondropathies & $3.32(1.80$ to 6.10$)$ & 8.44 (6.27 to 11.36$)$ & 3.97 (3.18 to 4.95$)$ \\
\hline Disorders of bone density and structure & $5.09(0.82$ to 31.50$) \dagger$ & $22.22(13.08$ to 37.74$)$ & 9.89 (6.89 to 14.19$)$ \\
\hline Soft tissue disorders & 2.41 (1.70 to 3.42$)$ & 1.99 (1.77 to 2.24$)$ & $1.86(1.69$ to 2.05$)$ \\
\hline Connective tissue disorders & (no admissions) & $0.98(0.38$ to 2.54$)$ & $0.92(0.44$ to 1.90$)$ \\
\hline
\end{tabular}

*Severe: TBSA 20\%+; minor TBSA<20\%; unspecified: TBSA unknown.

†All models were adjusted for sociodemographic (age group, gender, Aboriginal status, social disadvantage, remoteness), index year and health (comorbidity, prior musculoskeletal admission) status.

IRR, incidence rate ratios; TBSA, total body surface area. 
Table 4 Adjusted HRs for first time post-burn admissions for musculoskeletal subconditions, comparing the burn cohort with the uninjured cohort

\begin{tabular}{|c|c|c|c|}
\hline Musculoskeletal subconditions $\dagger$ & $\mathrm{HR}(95 \% \mathrm{Cl})^{\star}$ & $\begin{array}{l}\text { Attributable } \\
\text { risk \%* }\end{array}$ & $\begin{array}{l}\text { Number of admissions } \\
\text { attributable to burn } \\
\text { injury }\end{array}$ \\
\hline \multicolumn{4}{|l|}{ Arthropathies } \\
\hline $0-1$ year after burn & $2.02(1.58$ to 2.57$)$ & 50.5 & 47 \\
\hline $1-20$ years after burn & $1.26(1.17$ to 1.37$)$ & 20.6 & 154 \\
\hline \multicolumn{4}{|l|}{ Infectious arthropathy } \\
\hline $0-20$ years after burn & 2.34 (1.33 to 4.10$)$ & 57.3 & 11 \\
\hline \multicolumn{4}{|l|}{ Inflammatory polyarthropathy } \\
\hline $0-33$ years after burn & 1.68 (1.27 to 2.21$)$ & 40.5 & 27 \\
\hline \multicolumn{4}{|l|}{ Dorsopathies } \\
\hline $0-20$ years after burn & 1.39 (1.24 to 1.55$)$ & 28.1 & 114 \\
\hline \multicolumn{4}{|l|}{ Osteopathies and chondropathies } \\
\hline $0-1$ year after burn & 6.99 (3.94 to 12.41$)$ & 85.7 & 23 \\
\hline $1-5$ years after burn & 3.08 (2.12 to 4.48$)$ & 67.5 & 31 \\
\hline $5-20$ years after burn & 1.69 (1.29 to 2.23$)$ & 40.8 & 28 \\
\hline \multicolumn{4}{|c|}{ Disorders of bone density and structure } \\
\hline $0-2$ years after burn & 7.14 (4.11 to 12.40$)$ & 86.0 & 11 \\
\hline $2-33$ years after burn & $1.78(1.27$ to 2.51$)$ & 43.8 & 18 \\
\hline \multicolumn{4}{|l|}{ Soft tissue disorders } \\
\hline $0-10$ years after burn & $1.74(1.52$ to 1.99$)$ & 42.5 & 120 \\
\hline $10-33$ years after burn & 1.24 (1.08 to 1.42$)$ & 19.4 & 50 \\
\hline Total & & & 567 \\
\hline
\end{tabular}

more immediately after the burn injury. All subconditions showed significantly higher rates of first admissions in the first 20 years after burn. The AR\% calculated suggested that 567 first admissions to hospital for musculoskeletal diseases could be attributed to burn injury. The largest proportion of these incident admissions attributable to the burn injury were for arthropathies $(35.4 \%)$, followed by diseases of soft tissue $(30.0 \%)$, dorsopathies $(20.0 \%)$ and finally, osteopathies and chrondropathies $(14.5 \%)$.

\section{DISCUSSION}

This study quantifies the increased population-based long-term hospital use for musculoskeletal disorders experienced by adults hospitalised with burn injury, after controlling for demographic and pre-existing comorbidities. Members of the burn injury cohort had 1.98 times the rate of hospitalisations and 3.70 times the length of stay in hospital for combined musculoskeletal disorders post-burn when compared with the uninjured cohort. Arthropathies and dorospathies combined accounted for $74 \%$ of all readmissions (prevalent and incident disease admissions) for musculoskeletal disorders. After controlling for sociodemographic and pre-existing health status, the burn cohort experienced significantly higher rates of hospitalisations post-burn for arthropathies, dorsopathies, osteopathies and chrondropathies and soft tissue disorders. No difference was found for admission rates for diseases of the connective tissue when compared with the uninjured cohort.

Assessment of the impact of burn severity on recurrent admissions for musculoskeletal diseases identified significantly elevated rates of similar magnitude for severe and minor burn injury for arthropathies, dorsopathies and soft tissue disorders. However, while admission rates for osteopathies and chrondropathies were significantly elevated for severe burns (3.32 times higher), minor burns were associated with an admisson rate of 8.44 times that observed for the uninjured cohort over the study period. This lack of a dose-response relationship may in part be due to the small numbers of burn survivors with severe burns in this patient population, the TBSA classification used and/ or a 'healthy' survivor effect. An additional possibility is that patients with severe burns have supportive treatments to mitigate systemic inflammatory and endocrine responses and are more likely to have higher levels of continued post-burn care that may lead to earlier diagnoses and management of secondary pathologies, resulting in reduced hospitalisations for more serious presentations. The impact of minor burn injury on musculoskeletal disease admissions is interesting in light of recent evidence of less severe burn causing depletion of trabecular bone volume. ${ }^{27}$

To exclude any potential additive systemic impacts associated with other non-burn injury among members of the burn cohort, ${ }^{43}{ }^{44}$ first time admissions for musculoskeletal diseases post-burn were examined excluding 
those in the burn cohort with a principal diagnosis injury admission. After adjustment for sociodemographic and health factors, significantly elevated rates of first time post-burn hospitalisations for musculoskeletal disorders were identified. The adjusted AR\% for incident postburn musculoskeletal disease admissions suggested that 567 first time admissions experienced in the burn cohort after discharge, could be attributed to burn injury. Gender-specific analyses found males and females with burn injury to have significantly elevated admission rates.

Long-term admissions for infectious and inflammatory arthropathies were assessed as a means to investigate the potential for chronic impacts of the initial systemic inflammatory and immune response to burn injury. ${ }^{45-47}$ Significantly increased incident admission rates for infectious and inflammatory arthropathies post-burn were identified with effects persisting for at least 20 years, suggesting that burn patients are at increased long-term susceptibility to infectious and inflammatory diseases. The increases in inflammatory and infectious diseases may be related to the immune suppression induced by burn injury; ${ }^{46} 48 \quad 49$ however, recent evidence also suggests long-term changes in the immune response post-burn, including reduced dendritic cell activation and inability of dendritic cells to activate T cells. ${ }^{44}$ While the findings of considerably elevated incident admission rates for bone density disorders during the first 2 years post-burn were consistent with other research, ${ }^{7} 1114152122$ the burn cohort continued to experience significantly elevated incident admissions over the 33-year study period. Burn injury affects multiple systems of the body including the immune, metabolic and endocrine systems, and the pathophysiological mechanisms that underlie the different musculoskeletal conditions discussed in this paper are most likely variable. Future research will be important to identify how burn injury triggers different mechanisms in order to inform early intervention and prevent these long-term pathologies.

\section{Strengths and limitations}

Through the use of linked administrative health data, we performed a large scale population-based study with a long follow-up time, accurate pre- and post burn injury measures, ${ }^{50}$ a non-injured comparison group and sample size sufficient for quantitative analyses. The analytical strategy of the study was based on the assumption that after controlling for confounders, any excess in hospital use for musculoskeletal diseases in the burn cohort (compared to the non-injured), was an outcome principally associated with the incident burn. We were able to include variables of health, social disadvantage and geographic access to services, to determine the individual burden of hospital readmissions for musculoskeletal disorders and quantify at the population level. While health administrative datasets do not include variables of risk-taking behaviour, analyses undertaken of the burn cohort excluding members with a record of a non-burn injury admission and potentially those of high risk-taking behaviour, also found significantly elevated incident musculoskeletal admission rates. Likewise, models were adjusted for social disadvantage, a factor previously correlated with lifestyle risk factors (eg, nutrition, smoking, alcohol) ${ }^{51} 52$ that could be associated with the burn exposure and the outcomes measured. Changes in ICD coding and incomplete TBSA\% data may have limited a complete understanding of burn severity on long-term hospital use; however, significantly increased admission rates were observed for severe and minor burns and burns of unspecified TBSA. Any differential effect of burn injury on the incidence of fractures could not be evaluated in this study due to the exclusion of any injury admissions (including fractures) in the comparator uninjured cohort. Further research is planned that will include a non-burn injury cohort where differences in long-term musculoskeletal morbidity will be examined, including fractures.

The out-of-state migration for Western Australia is consistently low at levels below 3\%; such losses were not anticipated to bias the results. ${ }^{53}$ This study represents burn injury and musculoskeletal diseases serious enough to require hospitalisation and the results may underestimate the impact of burn injury experienced in the community. Research of functional outcomes and quality-of-life of burn patients in Western Australia have provided valuable data on patients during the first year after discharge $;^{54}{ }^{55}$ however, this study has generated new information on the longer-term musculoskeletal morbidity experienced long after healing of the burn wound and cessation of attendance at outpatient burn clinics. Further work that links individuals' pharmaceutical and or primary care data with hospital data will provide a clearer picture of the time of diagnosis of secondary musculoskeletal pathologies and treatment pathways post-burn. We expect that these results would be generalisable to other countries of similar demographics and healthcare systems.

After adjustment of confounders, increased rates of first time admissions and readmissions for musculoskeletal diseases were identified for those with severe and minor burns when compared with a non-injured cohort. These findings highlight long-term effects of burn injury, including minor burn injury, on musculoskeletal morbidity. Further research is required that facilitates identification of at-risk patients, the mechanisms that may be responsible for these long-term effects and appropriate treatment pathways, to reduce the long-term morbidity associated with burns.

Acknowledgements The authors thank the staff of the Health Information Linkage Branch for access to the Western Australian Data Linkage System and for their assistance in obtaining the data, the WA Health Data Custodians for access to the core health datasets and the Western Australian Department of Health. The project was supported by the Raine Medical Research Foundation (Priming grant JMD). JMD is supported by Woodside Corporation. MWF is supported by Chevron Australia.

Contributors The manuscript, including related data, figures and tables has not been previously published and that the manuscript is not under 
consideration elsewhere. All authors have made contributions to the paper and authorised the submission: JMD designed the study, supported data analyses and interpretation and drafted manuscript. SMR provided data management, analyses and data interpretation. JHB provided statistical advice. MWF, SR and FMW contributed clinical interpretation. All authors contributed to manuscript preparation and critical revision.

Funding Project data costs were supported by a Raine Medical Research Foundation Priming grant (JMD). JMD is supported by Woodside corporate sponsorship and the Fiona Wood Foundation. MWF is supported by Chevron Australia and the Fiona Wood Foundation.

Competing interests None declared.

Ethics approval This study has received ethics approval from the University of Western Australia and the Western Australian Department of Health. Being a large population cohort study using de-identified linked data, approval included a waiver of informed consent.

Provenance and peer review Not commissioned; externally peer reviewed.

Data sharing statement No additional data are available.

Open Access This is an Open Access article distributed in accordance with the Creative Commons Attribution Non Commercial (CC BY-NC 4.0) license, which permits others to distribute, remix, adapt, build upon this work noncommercially, and license their derivative works on different terms, provided the original work is properly cited and the use is non-commercial. See: http:// creativecommons.org/licenses/by-nc/4.0/

\section{REFERENCES}

1. Jeschke MG, Chinkes DL, Finnerty CC, et al. Pathophysiologic response to severe burn injury. Ann Surg 2008;248:387-401.

2. Przkora R, Barrow RE, Jeschke MG, et al. Body composition changes with time in pediatric burn patients. J Trauma 2006;60:968-71.

3. Przkora R, Jeschke MG, Barrow RE, et al. Metabolic and hormonal changes of severely burned children receiving long-term oxandrolone treatment. Ann Surg 2005;242:384-9, discussion 390-1.

4. Chang DW, DeSanti L, Demling RH. Anticatabolic and anabolic strategies in critical illness: a review of current treatment modalities. Shock 1998;103:155-60.

5. Rennie MJ. Muscle wasting in the muscular dystrophies. Dev Med Child Neurol 1985;27:524-7.

6. Rennie MJ. Muscle protein turnover and the wasting due to injury and disease. Br Med Bull 1985;41:257-64.

7. Klein GL. Burn-induced bone loss: importance, mechanisms, and management. J Burns Wounds 2006;5:e5

8. Klein GL, Wolf SE, Goodman WG, et al. The management of acute bone loss in severe catabolism due to burn injury. Horm Res 1997;48(Suppl 5):83-7.

9. Leblebici B, Sezgin N, Ulusan SN, et al. Bone loss during the acute stage following burn injury. J Burn Care Res 2008;29:763-7.

10. Klein GL, Bi LX, Sherrard DJ, et al. Evidence supporting a role of glucocorticoids in short-term bone loss in burned children. Osteoporos Int 2004;15:468-74.

11. Klein GL, Herndon DN, Goodman WG, et al. Histomorphometric and biochemical characterization of bone following acute severe burns in children. Bone 1995;17:455-60.

12. Garrel D. Burn scars: a new cause of vitamin D deficiency? Lancet 2004;363:259-60.

13. Klein GL. The interaction between burn injury and vitamin $D$ metabolism and consequences for the patient. Curr Clin Pharmacol 2008;3:204-10.

14. Klein GL. Burns: where has all the calcium (and vitamin D) gone? Adv Nutrition 2011;2:457-62.

15. Klein GL. Does vitamin D deficiency contribute to post-burn bone loss? F1000Res 2012;1:57.

16. Norman AW. Sunlight, season, skin pigmentation, vitamin D, and 25-hydroxyvitamin D: integral components of the vitamin D endocrine system. Am J Clin Nutr 1998;67:1108-10.

17. Klein GL, Langman CB, Herndon DN. Persistent hypoparathyroidism following magnesium repletion in burn-injured children. Pediatr Nephrol 2000;14:301-4.

18. Murphey ED, Chattopadhyay N, Bai M, et al. Up-regulation of the parathyroid calcium-sensing receptor after burn injury in sheep: a potential contributory factor to postburn hypocalcemia. Crit Care Med 2000;28:3885-90.
19. Gottschlich MM, Alexander JW. Fat kinetics and recommended dietary intake in burns. JPEN J Parenter Enteral Nutr 1987;11:80-5.

20. Gottschlich MM, Jenkins M, Warden GD, et al. Differential effects of three enteral dietary regimens on selected outcome variables in burn patients. JPEN J Parenter Enteral Nutr 1990;14:225-36.

21. Mayes T, Gottschlich M, Scanlon J, et al. Four-year review of burns as an etiologic factor in the development of long bone fractures in pediatric patients. J Burn Care Rehabil 2003;24:279-84.

22. Edelman LS, McNaught T, Chan GM, et al. Sustained bone mineral density changes after burn injury. J Surg Res 2003;114:172-8.

23. Akerlund E, Huss FR, Sjoberg F. Burns in Sweden: an analysis of 24,538 cases during the period 1987-2004. Burns 2007;33:31-6.

24. Duke J, Wood F, Semmens J, et al. A 26-year population-based study of burn injury hospital admissions in Western Australia. J Burn Care Res 2011:32:379-86.

25. Rea S, Giles NL, Webb S, et al. Bone marrow-derived cells in the healing burn wound-more than just inflammation. Burns 2009;35:356-64.

26. Anderson JR, Zorbas JS, Phillips JK, et al. Systemic decreases in cutaneous innervation after burn injury. J Invest Dermatol 2010;130:1948-51.

27. O'Halloran E, Kular J, Xu J, et al. Non-severe burn injury leads to depletion of bone volume that can be ameliorated by inhibiting TNF-alpha. Burns 2015;41:558-64

28. Morellini NM, Fear MW, Rea S, et al. Burn injury has a systemic effect on reinnervation of skin and restoration of nociceptive function Wound Repair Regen 2012;20:367-77.

29. Duke J, Rea S, Semmens J, et al. Burn Injury and cancer risk: a state-wide longitudinal study. Burns 2011;38:340-7.

30. Duke JM, Bauer J, Fear MW, et al. Burn injury, gender and cancer risk: population-based cohort study using data from Scotland and Western Australia. BMJ Open 2014;4:e003845.

31. Duke JM, Boyd JH, Rea S, et al. Long-term mortality among older adults with burn injury: a population-based study in Australia. Bull World Health Organ 2015;93:400-6.

32. Duke JM, Rea S, Boyd JH, et al. Mortality after burn injury in children: a 33-year population-based study. Pediatrics 2015;135: e903-10.

33. Hendrie D, Miller TR. Assessing the burden of injuries: competing measures. Inj Control Saf Promot 2004;11:193-9.

34. Holman CD, Bass AJ, Rouse IL, et al. Population-based linkage of health records in Western Australia: development of a health service research linked database. Aust NZ J Public Health 1999;23:453-9.

35. Glover J, Tennant S. Remote areas statistical geography in Australia: notes on the Accessibility/Remoteness Index for Australia (ARIA+ version). Working Papers Series No. 9. Adelaide: Public Health Information Development Unit, Adelaide, The University of Adelaide, 2003

36. Trewin D. Socio-economic indexes for areas (information paper, census of population and housing). Canberra: Australian Bureau of Statistics, 2003.

37. Charlson ME, Pompei P, Ales KL, et al. A new method of classifying prognostic comorbidity in longitudinal studies: development and validation. J Chronic Dis 1987;40:373-83.

38. Preen DB, Holman CDAJ, Spilsbury K, et al. Length of comorbidity lookback period affected regression model performance of administrative health data. J Clin Epidemiol 2006;59:940-6.

39. Ministry of Health-Manatu Haurora NZ. Mapping between ICD-10 and ICD-9. Secondary Mapping between ICD-10 and ICD-9. 30 May 2015. http://www.health.govt.nz/nz-health-statistics/data-references/ mapping-tools/mapping-between-icd-10-and-icd-9

40. Hosmer DW, Lemeshow S. Applied survival analysis: regression modeling of time to event data. New York: Wiley, 1999.

41. Hosmer DW, Royston P. Using Aalen's linear hazards model to investigate time-varying effects in the proportional hazards regression model. Stata J 2002;2:331-50.

42. Gordis L. Epidemiology. 2nd edn. Philadelphia: W.B. Saunders Company, 2000

43. Cameron CM, Purdie DM, Kliewer EV et al. Ten-year health service use outcomes in a population-based cohort of 21,000 injured adults: the Manitoba injury outcome study. Bull World Health Organ 2006;84:802-10.

44. Valvis SM, Waithman J, Wood FM, et al. The Immune Response to Skin Trauma is Dependent on the Etilology of Injury in a Mouse Model of Burn and Excision. J Invest Dermatol 2015;135:2119-28.

45. Mace JE, Park MS, Mora AG, et al. Differential expression of the immunoinflammatory response in trauma patients: burn vs. non-burn. Burns 2012;38:599-606.

46. O'Sullivan ST, O'Connor TP. Immunosuppression following thermal injury: the pathogenesis of immunodysfunction. Br J Plast Surg 1997;50:615-23. 
47. Rock KL, Lai JJ, Kono H. Innate and adaptive immune responses to cell death. Immunol Rev 2011;243:191-205.

48. D'Arpa N, Accardo-Palumbo A, Amato G, et al. Circulating dendritic cells following burn. Burns 2009;35:513-18.

49. Patenaude J, D'Elia M, Hamelin C, et al. Selective effect of burn injury on splenic CD11C(+) dendritic cells and CD8alpha(+)CD4(-) CD11c(+) dendritic cell subsets. Cell Mol Life Sci 2010;67:1315-29.

50. Department of Health Western Australia. Clinical Information Audit Program-Hospital Activity Report. Operational Directive OD 0201/ 09. Perth Department of Health WA, 2009.

51. Mishra G, Ball K, Patterson A, et al. Socio-demographic inequalities in the diets of mid-aged Australian women. Eur J Clin Nutr 2005;59:185-95.
52. Siahpush M, Borland R, Scollo M. Prevalence and socio-economic correlates of smoking among lone mothers in Australia. Aust NZ J Public Health 2002;26:132-5.

53. Clark A, Preen DB, Ng JQ, et al. Is Western Australia representative of other Australian States and Territories in terms of key socio-demographic and health economic indicators? Aust Health Rev 2010;34:210-15.

54. Grisbrook TL, Elliott CM, Edgar DW, et al. Burn-injured adults with long term functional impairments demonstrate the same response to resistance training as uninjured controls. Burns 2013;39:680-6.

55. Grisbrook TL, Reid SL, Edgar DW, et al. Exercise training to improve health related quality of life in long term survivors of major burn injury: a matched controlled study. Burns 2012;38:1165-73. 